\title{
Review of statutory and voluntary labelling of food allergens*
}

\author{
Mark Boden, Ruth Dadswell and Sue Hattersley ${ }^{\dagger}$ \\ Food Standards Agency, Aviation House, 125 Kingsway, London WC2B 6NH, UK
}

\begin{abstract}
Food allergy represents an increasingly important health problem, with prevalence in Western Europe continuing to rise. While some reactions are mild, others can include life-threatening anaphylactic shock. It is estimated that food allergies affect $1-2 \%$ of the adult population and $\leq 8 \%$ of children. Relatively few foods are to blame for a large majority of allergic reactions to food in the UK, with most reactions being to milk, eggs, peanuts (Arachis hypogea), nuts, fish, shellfish, soyabean, sesame (Sesamum indicum L.) and wheat. There is currently no cure for food allergy and the few available treatments are focused on relieving the specific symptoms. Consumers with food allergies and food intolerances rely on food labelling to enable them to make informed choices about the foods they eat. Whilst there have recently been important advances in the labelling of food allergens, these advances relate only to requirements for the labelling of the deliberate use of specified food allergens in foods sold pre-packed. In other areas the development of guidance for food manufacturers and retailers on how to assess the risks of possible allergen cross-contamination during food production and manufacture, and then to determine appropriate advisory labelling, is well advanced. Work to address the issue of how to provide appropriate allergen information for foods sold loose, or in catering establishments, is also in progress.
\end{abstract}

Food allergens: Labelling: Legislation: Voluntary guidance

Food intolerance and food allergy are both types of food sensitivity. In the past the term 'intolerance' was used as a generic term and included food allergies. However, more recently, the generic terms 'food sensitivity' or 'food hypersensitivity' have been used increasingly to describe both food allergy and food intolerance (Johansson et al. 2004).

Food intolerance is a reproducible adverse reaction to a food or food ingredient that does not involve the immune system. It is used to describe a range of adverse responses to food, including reactions resulting from enzyme deficiencies and pharmacological effects. Examples of food intolerance include lactose intolerance or reactions to histamine found naturally in some foods.

Food allergy can be defined as a reproducible adverse reaction to a food or food ingredient that involves the immune system. The foods that most commonly trigger allergic reactions in the UK and Europe are peanuts (Arachis hypogea), tree nuts (which include cashew (Anacardium occidentale L.), almond (Amygdalus communis L.), hazelnut (Corylus avellana), pecan (Carya illinoensis (Wangenh.) K. koch), walnut (Juglans regia), Brazil nut (Bertolletia excelsa), pistachio nut (Pistacia vera) and macedemia nut and Queensland nut (Macedemia temifolia)), fish and shellfish, eggs and milk (Young et al. 1994; Food and Agriculture Organization, 1995). The majority of these reactions are mediated by $\operatorname{IgE}$, which is part of the normal immune system response to foreign proteins that in those individuals with food allergies is inappropriately directed towards everyday food constituents.

Allergic reactions mediated by $\mathrm{IgE}$ are immediate and can be severe, triggering the immune system, in particular mast cells, to release inflammatory products such as histamine. Mast cells are present below the surface of the skin and in the membranes of the eyes, nose, respiratory tract and intestine. When triggered, the release of histamine from these mast cells causes symptoms such as itchy rashes, rhinitis, asthma, eczema, dilation of blood vessels, flushing, swelling (e.g. of the lips and face), difficulty breathing and ultimately collapse. These symptoms can appear within minutes or up to several hours after the individual has eaten the food to which they are allergic (Taylor, 1987).

Although food allergies are normally mediated via $\operatorname{IgE}$, in coeliac disease (also known as gluten intolerance or gluten sensitivity) the reaction is mediated by a different

\footnotetext{
*The opinions expressed in the present paper represent the opinions of the authors and do not represent the views of the Food Standards Agency. $\dagger$ Corresponding author: Mrs Sue Hattersley, fax +44 207276 8513, email sue.hattersley@ foodstandards.gsi.gov.uk
} 
$\mathrm{Ig}, \mathrm{IgG}$, and the types of reaction experienced in individuals with coeliac disease are distinct from those experienced by individuals with a food allergy. In such individuals consumption of gluten (a storage protein found in wheat, rye, barley and oats) causes intestinal villous atrophy (flattening) and its physiological consequences of malabsorption and malnutrition.

It is widely accepted that the prevalence of food allergy in general is increasing in line with other atopic conditions (Howarth, 1998; Committee on Toxicity of Chemicals in Food, Consumer Products and the Environment, 2002; UK Parliament Health Committee, 2004). The prevalence of allergies to particular foods is not known, although $\leq 20$ $30 \%$ of the general population perceive themselves to have a food allergy or some other adverse reaction to food (Young et al. 1994; Committee on Toxicity of Chemicals in Food, Consumer Products and the Environment, 2002; Woods et al. 2002). However, the true prevalence of food allergy is estimated to be between 1 and $2 \%$ in adults and approximately $5-8 \%$ in children (Helm \& Burks, 2000).

In Western Europe and the USA most immunological adverse reactions are caused by a limited number of foods. The prevalence of allergy to particular foods varies geographically, probably as a result of different regional dietary practices and dissimilar exposure to allergens (Hourihane, 1998). Peanuts, tree nuts, fish and shellfish cause the majority of allergic reactions in adults in the UK. In children $90 \%$ of the reactions are caused by cow's milk, chicken's eggs, wheat, peanuts, tree nuts and soyabean protein. Allergy to cow's milk is the most common food allergy in childhood and affects $2-7 \%$ of babies $>1$ year old. It is more common in babies with atopic dermatitis. A baby who has cow's milk allergy can react to small amounts of milk protein that are either passed to the baby through the mother's breast milk from dairy products she has eaten, or derived from cow's milk or formula based on cow's milk given to the baby.

A key aim of the Food Standards Agency, set out in the 2005-10 Strategic Plan (Food Standards Agency, 2005), is to enable consumers to make informed choices. There is no cure for food allergy and those individuals affected have to adopt management strategies to ensure that they do not consume even small amounts of the foods to which they react. Thus, they need information from food manufacturers, retailers and caterers. Discrepancies between food content and labels can lead to adverse reactions in individuals with sensitivity to particular food components. Conversely, overuse of precautionary labelling can unnecessarily restrict consumer choice and devalue the labelling itself.

\section{Types of allergen labelling}

Labelling information requirements are covered by legislation, which sets out the sort of information that needs to be provided, and can also prescribe how that information is presented. For example, the ingredients present in a food have to be listed in decreasing order by weight. Most food labelling requirements in the $\mathrm{UK}$ are set out in European legislation, which is then implemented in national legislation, with parallel provisions made in England, Scotland, Wales and Northern Ireland.

However, food manufacturers and retailers may decide voluntarily to provide additional information, beyond what is set out in the legislation. Whilst this information may be helpful for consumers, there can sometimes be confusion if such information is not provided in a consistent way. In such situations, the development of 'best practice' guidance may be helpful.

\section{Statutory labelling requirements}

The labelling of most food in the UK is governed by the provisions of the Food Safety Act 1990 (UK Parliament, 1990) and the Food Labelling Regulations 1996 (UK Parliament, 1996) and its subsequent amendments, which set out provisions for the labelling, presentation and advertising of food. The Food Labelling Regulations 1996 (UK Parliament, 1996) require that most pre-packed foods, subject to certain exemptions, carry: a name; a list of ingredients and the amount of the main ingredient used; a date mark; any special storage conditions or conditions of use; the name and address of the manufacturer, packer or EU seller; instructions for use; the place of origin of the food, if failure to give this information might mislead the consumer.

In addition to these provisions, Directive 2000/13/EC of the European Parliament (European Commission, 2000; which consolidates Council Directive 79/112/EEC (European Commission, 1979)) sets out general requirements relating to the listing of ingredients used in foods. However, this legislation contained a number of exemptions that meant that the consumer with food allergies or food intolerances would not always have access to all the information they needed. For example, there was a provision (commonly known as the $25 \%$ rule) that meant that if a compound food (e.g. a sponge finger in a trifle or a sausage as a topping on a pizza) made up $<25 \%$ of the final food, then there was no legal requirement to list all the ingredients used in that compound food ingredient. The consequences of this provision led to pressure for Directive 2000/13/EC (European Commission, 2000) to be amended so that there would be a requirement for full ingredient listing for common food allergens.

The European Directive 2003/89/EC (European Commission, 2003), which amends Directive 2000/13/EC, came into effect in November 2004. This legislation establishes a list of allergenic food ingredients that must be indicated on the label when they or their derivatives are used in food sold pre-packed in the EU. This legislation has a wide scope and includes all food ingredients, including carryover additives, additives used as processing aids, solvents and media for additives and flavourings. The provisions also apply to alcoholic beverages. New national rules that amend the Food Labelling Regulations 1996 (UK Parliament, 1996) and implement Directive 2003/89/EC (European Commission, 2003) were implemented in 2004 in England by the Food Labelling (Amendment) (No. 2) Regulations 2004 (UK Parliament, 2004), and there is parallel legislation in Scotland (Scottish Parliament, 2004), 
Wales (National Assembly of Wales, 2004) and Northern Ireland (Northern Ireland Assembly, 2004).

Directive 2003/89/EC (European Commission, 2003) abolishes the $25 \%$ compound ingredient exemption, and some other existing labelling exemptions will no longer be accepted for allergens. Previously, it was possible to declare some ingredients only as a category, such as vegetable oil. The new rules will require that the source is indicated for all allergenic ingredients, so that, for example, if vegetable oil contains peanut oil it must be specified in the label. Similarly, the source of a natural flavour such as a nut will have to be indicated, rather than being labelled only as 'natural flavour'.

Annex IIIa of Directive 2003/89/EC (European Commission, 2003) currently lists twelve allergenic foods and food ingredients (cereals containing gluten, crustaceans eggs, milk, fish, peanuts (Arachis hypogea), soyabeans, nuts, sesame (Sesamum indicum L.) seeds, celery (Apium graveolens), mustard (Sinapsis alba L.) and sulphite $(10 \mathrm{mg} / \mathrm{kg}$ or $>10 \mathrm{mg} / \mathrm{l}))$ for which labelling is required. Whenever the listed ingredients are used in the production of foodstuffs, they must be labelled. However, some individuals are sensitive to allergens that are not on the list, and so it is important that they continue to check ingredients lists carefully. Furthermore, allergenic foods can be added to this list on the advice of the European Food Safety Authority.

There is a transitional period of 1 year in the implementation of this Directive to enable food manufacturers to make the necessary changes to food labels. Thus, products without this labelling cannot be marketed after 25 November 2005, although products already labelled before this time can continue to be sold, whilst stocks last.

A number of factors are responsible for determining whether or not, after exposure to an allergen, an individual with an allergy will experience an adverse reaction. For example, in the case of peanuts some individuals react to as little as $0.1 \mathrm{mg}$ peanut protein, while others can tolerate $\leq 1 \mathrm{~g}$ before suffering an allergic reaction. In addition, as well as inter-individual variability, there is also variability in the same individual on different occasions. For example, for individuals whose allergic reactions to foods include respiratory symptoms, adverse reactions to a given amount of the food allergen can be markedly more severe when concurrent asthma is poorly controlled. Thus, it is not possible to set definitive thresholds for acceptable levels of the different food allergens, as is common practice for setting acceptable levels of chemicals in food (European Food Safety Authority, 2004).

However, some highly processed food ingredients derived from these listed allergenic foods are very unlikely to pose a threat for consumers with food allergies. In addition, other substances that may trigger allergic reactions can be used in such a way that the finished product would not be a risk for individuals with food allergies. During the negotiations on Directive 2003/89/EC (European Commission, 2003), the European Commission accepted that provision should be made for exemption from the labelling requirements for those derivatives that could be demonstrated not to pose a risk to consumers with an allergy. The food industry was therefore invited to submit dossiers of existing information to the European Food Safety Authority to support the exemption of certain derived products. Those derived products that the European Food Safety Authority considered, on the basis of the existing information, to be unlikely to trigger reactions in consumers with an allergy will be exempt, on a provisional basis, from the labelling requirements of 2003/ 89/EC (European Commission, 2003) that come into force in November 2005. However, industry will have to submit further information on these ingredients for evaluation by the European Food Safety Authority so that a final list of exempt derived ingredients can be developed.

This list of provisionally-exempt derived ingredients (see Table 1) has now been published as an Annex to Directive 2005/26/EC (European Commission, 2005), and a permanent list of exemptions is scheduled to be published by November 2007. Fully-refined peanut oil is not included on this list of exempt derived ingredients because the European Food Safety Authority was of the opinion that, on the basis of existing information, it was possible that this ingredient could cause allergic reactions in individuals who are highly allergic to peanuts. This ruling will have implications both for the food industry, who will have to specifically label the use of this oil, and for consumers who are allergic to peanuts, whose food choices will be further restricted. However, it is possible that further information that would support the exemption of this ingredient could be submitted for evaluation by the European Food Safety Authority.

\section{Voluntary initiatives}

As mentioned earlier, some food manufacturers and retailers want to go beyond the statutory labelling requirements and provide additional information for consumers about their products. One area in which such additional information is increasingly being provided relates to the possibility of cross-contamination with allergens during food manufacturing. To date, this information has predominantly referred to possible cross-contamination with nuts and is often indicated using phrases such as "may contain nuts'. Additionally, whilst allergen-labelling legislation, like most food-labelling legislation, is applicable only to pre-packed foods, there is increasing demand from consumers with food allergies for allergen information about foods sold non-pre-packed. This category can include foods sold loose, such as in a bakery or at a delicatessen counter, food sold pre-packed for direct sale, such as sandwiches, or foods sold in catering establishments.

\section{'May contain'}

Consumers who shop for individuals with food allergies and intolerances need clear specific labelling of both deliberate allergenic ingredients and possible crosscontamination in order to be able to make informed food choices. The presence of an undeclared, unintended allergen in food destined for consumption is potentially lifethreatening. However, modern processing methods mean that foods not intended to contain a particular allergenic 
Table 1. List of food ingredients and substances provisionally excluded from Annex IIla of Directive 2000/13/EC (European Commission, 2000) as amended by Directive 2003/89/EC (European Commission, 2003), based on opinions from the European Food Safety Authority Panel on Dietetic Foods, Nutrition and Allergy (European Food Safety Authority, 2004-5)

\begin{tabular}{ll}
\hline Ingredients & Products thereof provisionally \\
excluded \\
\hline Cereals containing & Wheat-based glucose syrups \\
gluten & including dextrose \\
& Wheat-based maltodextrins \\
& Glucose syrups based on barley \\
& Cereals used in distillates for \\
& spirits \\
& Lysozyme (produced from egg) \\
Egged in wine & Albumin (produced from egg) \\
& used as a fining (clarifying) \\
& agent in wine and cider \\
& Fish gelatine used as a carrier \\
for vitamins and flavours \\
Fish gelatine or isinglass used as \\
a fining agent in beer, cider \\
and wine \\
Fully-refined soyabean oil and fat \\
Natural mixed tocopherols \\
(E306), natural D- $\alpha$-tocopheryl \\
succinate from soyabean \\
sources \\
Phytosterols and phytosterol \\
esters derived from vegetable \\
oils obtained from soyabean \\
sources \\
Plant stanol ester produced from \\
vegetable oil sterols from \\
soyabean sources \\
Whey used in distillates for spirits \\
Lactitol \\
Milk (casein) products used as \\
fining agents in cider and wines \\
Nuts used in distillates for spirits \\
Nuts (almonds (Amygdalus \\
communis L.), walnuts \\
(Juglans regia)) used (as \\
flavour) in spirits \\
Celery leaf and seed oil \\
Celery seed oleoresin \\
Mustard oil \\
Mustard seed oil \\
Mustard seed oleoresin
\end{tabular}

ingredient may be produced in the same factory, or even on the same production line, as one containing that ingredient. For example, plain biscuits may be made on the same production line as the nut-containing variety. The potential for allergen contamination of the plain product that is normally suitable for an individual with an allergy can be important.

The statutory labelling requirements for the allergenic foods listed in Directive 2003/89/EC (European Commission, 2003) do not cover the unintentional presence of those allergens in pre-packed foods that can result from cross-contamination with the allergen at some point during the manufacture or transport of the food. Whilst it is helpful for those individuals with severe food allergies to be alerted to such possible cross-contamination, there is general agreement between the food industry, consumers and enforcement bodies that excessive use of these foodallergen warning labels not only restricts consumer choice but also devalues the impact of warnings. There is also concern that the variability between different food manufacturers and retailers in the way in which they convey information about possible allergen cross-contamination leads to consumer confusion. In addition, such advisory labelling is felt by some consumers to be difficult to find and difficult to see.

At the end of 1997 the Ministry of Agriculture, Fisheries and Food wrote to food manufacturers and retailers, asking them to improve their quality control measures and manufacturing processes in order to avoid the use of what was then called 'defensive labelling'. Some companies already had measures in place to minimise nut trace contamination and had introduced food labels such as 'may contain nuts' to warn consumers of the possible presence of nuts in the product.

However, since that time the use of 'may contain' warning labels on food products has increased. This situation may have been as a consequence of foods becoming more complex and/or in response to the increasing incidence of food allergy in the UK population. Research conducted for the Food Standards Agency in 2001 and 2002 (Anaphylaxis Campaign, 2001; COI Communications, 2002) has identified this issue as a major problem for consumers with food allergies. The use of logos, wording, style and format was found to vary markedly between different products and between different retailers, as did the process used to decide whether to use nut trace contamination labelling (Anaphylaxis Campaign, 2001; COI Communications, 2002). Following discussions with all stakeholders (food industry, consumers and enforcement bodies), the Food Standards Agency (2005) has made a commitment to produce 'best practice' guidance on this issue by 2006. This guidance, which is being produced in consultation with all interested stakeholders, provides advice for food producers and retailers on how to assess the risks of cross-contamination of a food product with an allergenic food or food ingredient. The outcome of such a risk assessment will then determine appropriate advisory labelling. It is also important that consumers with food allergies and food intolerances understand the meaning of any advisory labelling used on a product so that they can make appropriate food choices. A draft of this guidance will be the subject of a formal public consultation exercise, and it is anticipated that the final guidance will be published in 2006.

\section{Non-prepacked foods}

There is a diverse range of organisations and establishments that are involved in the provision of non-pre-packed foods for direct sale. These foods are often sold loose and through various outlets, including catering establishments. Anecdotal evidence suggests that most food-allergy 
incidents, including deaths, happen outside the home and can be traced to foods that are not pre-packed, such as those sold in catering establishments.

The Food Standards Agency (2004) has produced 'best practice' guidance for caterers to help them respond to customers who are seeking information about whether particular dishes sold in their establishment contain the ingredient to which the customer is sensitive. Although foods sold non-pre-packed are currently exempt from the allergen-labelling legislation, the Food Standards Agency is consulting stakeholders with the aim of developing possible options for improving the provision of information on the use of allergens in such situations. Again, there will be a formal public consultation on the preferred options.

\section{Allergen labelling in other countries}

Although different legislation and guidelines have been developed by various national and international organisations, they often share some common themes. For example, the Food Standards Australia New Zealand (2002) advises that there are eight major allergens (seafood, milk, peanuts, tree nuts, sesame seeds, soyabean, wheat and eggs) that must be declared on the food label, however small the amount added. In the USA the Food Allergen Labelling and Consumer Protection Act (US Congress, 2004) will require, beginning from 1 January 2006, that food manufacturers identify, in plain common language, the presence of any of the eight major food allergens. The legislation requires that food labels indicate the presence of major food allergens used in flavourings, spices, additives and colourings. This Act also compels the Department of Health and Human Services to: improve the collection of food allergy data; convene a panel of experts to review food allergy research efforts; report to Congress on the number of allergen inspections done of food manufacturing facilities over a 2-year period, and the ways in which these facilities can reduce or eliminate cross-contamination; consider revisions of the Food Code (Department of Health and Human Services, 2001) to provide allergen-free preparation guidelines for restaurants and food service establishment; investigate consumer preference pertaining to advisory food labelling such as precautionary 'may contain' statements.

\section{Conclusion}

Food labelling information is vitally important for those individuals who have food allergies to enable them to make informed choices about the foods they eat. Whilst there have recently been significant advances in the labelling of food allergens, these relate only to requirements for the labelling of the deliberate use of specified food allergens in foods sold pre-packed. In other areas the development of guidance for food manufacturers and retailers on how to assess the risks of possible allergen cross-contamination during food production and manufacture, and then to determine appropriate advisory labelling, is well advanced. Work to address the issue of how to provide appropriate allergen information for foods sold loose, or in catering establishments is also in progress.

\section{References}

Anaphylaxis Campaign (2001) 'May contain' labelling - The consumer's perspective. http://www.food.gov.uk/multimedia/ pdfs/maycontainreport.pdf

COI Communications (2002) Nut allergy labelling: Report of research into the consumer response. http://www.food.gov.uk/ multimedia/pdfs/nutallergyresearch.pdf

Committee on Toxicity of Chemicals in Food, Consumer Products and the Environment (2002) Adverse reactions to food and food ingredients. http://www.food.gov.uk/science/ ouradvisors/toxicity/reports/food reactions

Department of Health and Human Services (2001) Food code. http://www.cfsan.fda.gov/ dms/foodcode.html

European Commission (1979) Council Directive 79/112/EEC of 18 December 1978 on the approximation of the laws of the Member States relating to the labelling, presentation and advertising of foodstuffs for sale to the ultimate consumer. Official Journal of the European Commission L033, 1-14.

European Commission (2000) Directive 2000/13/EC of the European Parliament and of the Council of 20 March 2000 on the approximation of the laws of the Member States relating to the labelling, presentation and advertising of foodstuffs. Official Journal of the European Commission L109, $29-42$.

European Commission (2003) Directive 2003/89/EC of the European Parliament and of the Council of 10 November 2003 amending Directive 2000/13/EC as regards indication of the ingredients present in foodstuffs. Official Journal of the European Communities L308, 15-18.

European Commission (2005) Commission Directive 2005/26/EC of 21 March 2005 establishing a list of food ingredients or substances provisionally excluded from Annex IIIa of Directive 2000/13/EC of the European Parliament and of the Council. Official Journal of the European Commission L075, 33-34.

European Food Safety Authority (2004) Opinion of the Scientific Panel on Dietetic Products, Nutrition and Allergies on a request from the Commission relating to the evaluation of allergenic foods for labelling purposes (EFSA-Q-2003-016). http://www.efsa.eu.int/science/nda/nda_opinions/341_en.html

European Food Safety Authority (2004-5) Opinions of the Scientific Panel on Dietetic Products, Nutrition and Allergies (NDA). http://www.efsa.eu.int/science/nda/nda_opinions/catin dex_en.html

Food and Agriculture Organization (1995) Report of the FAO Technical Consultation on Food Allergies. Rome: FAO.

Food Standards Agency (2004) Advice for caterers on allergy and intolerance, May 2004. http://food/gov.uk/safereating/ allergyintol/caterers/

Food Standards Agency (2005) Strategic Plan 2005-2010 - Putting consumers first. http://www.food.gov.uk/multimedia/pdfs/ stratplan0510.pdf

Food Standards Australia New Zealand (2002) The Australia New Zealand Food Standards Code. http://www.food standards.gov.au/foodstandardscode/

Helm RM \& Burks AW (2000) Mechanisms of food allergy. Current Opinion in Immunology 12, 647-653.

Hourihane J (1998) Prevalence and severity of food allergy need for control. Allergy 53, Suppl. 46, 84-88.

Howarth PH (1998) Is allergy increasing? Early life influences. Clinical and Experimental Allergy 28, Suppl. 6, 2-7.

Johansson SG, Bieber T, Dahl R, Friedmann PS, Lanier BQ, Lockey RF et al. (2004) Revised nomenclature for allergy for 
global use: Report of the Nomenclature Review Committee of the World Allergy Organisation, October 2003. Journal of Allergy and Clinical Immunology 113, 832-836.

National Assembly of Wales (2004) Welsh Statutory Instrument 2004 No. 3022 (W.261). The Food Labelling (Amendment) (No. 2) (Wales) Regulations 2004 http://www.opsi.gov.uk/leg islation/wales/wsi2004/20043022e.htm

Northern Ireland Assembly (2004) Statutory Rule 2004 No. 469. Food Labelling (Amendment No. 2) Regulations (Northern Ireland) 2004. http://www.opsi.gov.uk/sr/sr2004/ 20040469.htm

Scottish Parliament (2004) Scottish Statutory Instrument 2004 No. 472. The Food Labelling Amendment (No. 2) (Scotland) Regulations 2004. http://www.opsi.gov.uk/legislation/scotland/ ssi2004/20040472.htm

Taylor SL (1987) Allergic and sensitivity reactions to food components. In Nutritional Toxicology, vol. II, pp. 173-197 [JN Hathcock, editor]. Orlando, FL: Academic Press.

UK Parliament (1990) Food Safety Act 1990 (c. 16). http:// www.opsi.gov.uk/acts/acts1990/Ukpga_19900016_en_1.htm
UK Parliament (1996) Statutory Instrument 1996 No. 1499. The Food Labelling Regulations 1996. http://www.opsi.gov.uk/si/ si1996/Uksi_19961499_en_1.htm

UK Parliament (2004) Statutory Instrument 2004 No. 2824. The Food Labelling (Amendment) (England) (No. 2) Regulations 2004. http://www.opsi.gov.uk/si/si2004/20042824.htm

UK Parliament Health Committee (2004) Health Committee Report, 2004. The provision of allergy services. http://www. publications.parliament.uk/pa/cm200304/cmselect/cmhealth/ 696/69602.htm

US Congress (2004) Food Allergen Labelling and Consumer Protection Act of 2004. http://www.cfsan.fda.gov/ dms/alr gact.html

Woods RK, Stoney RM, Raven J, Walters EH, Abramson M \& Thien FC (2002) Reported adverse reactions overestimate true food allergy in the community. European Journal of Clinical Nutrition 56, 31-36.

Young E, Stoneham MD, Petruckevitch A, Barton J \& Rona R (1994) A population study of food intolerance. Lancet 343, $1127-1130$. 